\title{
Strategy formulation for development of leather footwear centre based on capabilities and source of innovation (case study: leather footwear SMEs in Cibaduyut, Bandung)
}

\author{
R Fitriani $^{{ }^{*}}$, M L Singgih ${ }^{1 * *}$, and B Syairudin ${ }^{1 * * *}$ \\ ${ }^{1}$ Department of Industrial Engineering, Institut Teknologi Sepuluh Nopember, \\ Surabaya, Indonesia \\ *risma_fitriani1804@yahoo.co.id \\ **moseslsinggih@ie.its.ac.id \\ ***bambangsy@ie.its.ac.id
}

\begin{abstract}
Small and Medium Enterprises (SMEs) sector is one of an important element in the economic system in Indonesia. This kinds of sector have a major role in developing the employment procurement and the people's economic condition as well. Thus, it is expected to be well developed and organized. This study aims to identify the strategy used by SMEs based on the influence of SME's capabilities and source of innovation. This study was conducted by analyzing the influence of variable using structural equation models (SEM) to determine the indicators and variable that have significant influence on SMEs' capabilities and source of innovation; and classifying the indicator based on SWOT formulation as well. These indicator and variables are categorized into strength-opportunities (SO), strengths-threats (ST), weaknessopportunities (WO), and weakness-threats (WT). The result shows that the weakness-threats (WT) strategy has the most influence value in developing their capabilities and source of innovation. Therefore, the SMEs leather footwear centre in Cibaduyut should focus on the development strategy by considering their weaknesses to confront threats.
\end{abstract}

\section{Introduction}

Small and medium enterprises (SMEs) are one of the important elements in the economy of a country or region, including in Indonesia. As stated by The Finance Minister of Indonesia in 2015 in the festival of Ramadan that SMEs have an important role in encouraging the growth of the economy in Indonesian. Through the sector of SMEs, the unemployment rate is being reduced. The sectors of SMEs have also proven to be a strong pillar of the economy.

It has also been demonstrated during the economic crisis of 1998, that SMEs has survived from the economy collapse in Indonesia. The contribution of the SMEs in determining the Gross Domestic Product (GDP) and foreign exchange sector is also not in doubt. At present, SMEs have been used as the main agenda of economic development in Indonesia. According to The Finance Minister, government policies have shown their partiality to SMEs. In addition the government also conducts some promoting programs to increase small and medium enterprises in Indonesia as well as giving special attention to SMEs, such as stated in the Law No. 9 of 1995 concerning small business. 
SMEs in Indonesia has various types, one of them is SMEs engaged in the production of leather footwear, which are commonly known as SME centers leather footwear. According to the Agency for Industrial Development of Indonesia (BPIPI), leather footwear is one of the leading industries in Indonesia; particularly those located in Bandung, Yogyakarta, Magetan, Mojokerto and Sidoarjo. Among those locations, it is determined that the footwear business distribution area of Bandung (namely Shoes Center of Cibaduyut) experiences decreasing in the number of business units, which triggers new problems if it keeps decreasing in the next years.

Based on this condition, it appears to be necessary to find out the role of the capabilities of the SMEs and sources of innovation to increase productivity in order to generate greater revenue contribution for the coming years. Innovation is a form of creativity that was created as an added value and business excellence in order to compete productively. Innovation is widely recognized as the important capabilities and resources of the success and competitive advantage in a business (1). Thus, sources of innovation are the things that trigger to be the implementation of an innovation that could ultimately improve productivity. Table 1 shows the previous studies from other researcher.

Table 1. Research Position.

\begin{tabular}{ccccccc}
\hline Reseacher & $\mathbf{C}^{\mathbf{1}}$ & $\mathbf{P}^{2}$ & $\mathbf{S}^{3}$ & $\mathbf{S I}^{4}$ & $\mathbf{S E}^{5}$ & $\mathbf{P R}^{6}$ \\
\hline$(1)$ & $\mathrm{V}$ & & & $\mathrm{V}$ & $\mathrm{V}$ & $\mathrm{V}$ \\
$(2)$ & $\mathrm{V}$ & & & $\mathrm{V}$ & $\mathrm{V}$ & \\
$(3)$ & & $\mathrm{V}$ & & $\mathrm{V}$ & $\mathrm{V}$ & $\mathrm{V}$ \\
$(4)$ & & & & $\mathrm{V}$ & $\mathrm{V}$ & $\mathrm{V}$ \\
$(5)$ & $\mathrm{V}$ & & & $\mathrm{V}$ & $\mathrm{V}$ & $\mathrm{V}$ \\
$(6)$ & $\mathrm{V}$ & & & & & $\mathrm{V}$ \\
$(7)$ & $\mathrm{V}$ & & $\mathrm{V}$ & $\mathrm{V}$ & & $\mathrm{V}$ \\
$(8)$ & & $\mathrm{V}$ & $\mathrm{V}$ & & & $\mathrm{V}$ \\
$(9)$ & & & & $\mathrm{V}$ & & $\mathrm{V}$ \\
$(10)$ & $\mathrm{V}$ & & & $\mathrm{V}$ & $\mathrm{V}$ & \\
$(11)$ & $\mathrm{V}$ & & $\mathrm{V}$ & & $\mathrm{V}$ & \\
$(12)$ & $\mathrm{V}$ & & $\mathrm{V}$ & $\mathrm{V}$ & $\mathrm{V}$ & \\
\hline
\end{tabular}

\begin{tabular}{ccccccc}
\hline Reseacher & $\mathbf{C}^{1}$ & $\mathbf{P}^{2}$ & $\mathbf{S}^{3}$ & $\mathbf{S I}^{4}$ & $\mathbf{S E}^{5}$ & $\mathbf{P R}^{6}$ \\
\hline$(13)$ & & & $\mathrm{V}$ & $\mathrm{V}$ & $\mathrm{V}$ & \\
$(14)$ & $\mathrm{V}$ & & & & & $\mathrm{V}$ \\
$(15)$ & & $\mathrm{V}$ & & & & $\mathrm{V}$ \\
$(16)$ & & & & & & \\
$(17)$ & $\mathrm{V}$ & & & & & $\mathrm{V}$ \\
$(18)$ & $\mathrm{V}$ & $\mathrm{V}$ & & & & $\mathrm{V}$ \\
$(19)$ & $\mathrm{V}$ & & & $\mathrm{V}$ & $\mathrm{V}$ & \\
$(20)$ & $\mathrm{V}$ & & $\mathrm{V}$ & & & $\mathrm{V}$ \\
$(21)$ & & & $\mathrm{V}$ & $\mathrm{V}$ & $\mathrm{V}$ & $\mathrm{V}$ \\
$(22)$ & & & $\mathrm{V}$ & $\mathrm{V}$ & $\mathrm{V}$ & \\
This & & & & & & \\
Research & $\mathrm{V}$ & $\mathrm{V}$ & $\mathrm{V}$ & $\mathrm{V}$ & $\mathrm{V}$ & $\mathrm{V}$ \\
\hline
\end{tabular}

\footnotetext{
${ }^{1} \mathrm{C}$ : Organization Capability

${ }^{2} \mathrm{P}$ : Production

${ }^{3} \mathrm{~S}$ : Marketing system
}

Based on the previous studies, this study found the gap in determining the appropriate strategy for the development of SME. One of them can be seen from the side effects of these variables in supporting productivity. From the journal studies done previously, it could be concluded that there are variables and other indicators that have a role in increasing productivity, in terms of production, organization and marketing system. In addition to analysing the influence of these variables, formulating the right priority strategies development could also be applied based on the data of existing conditions of SMEs, which have been obtained through the analysis of the influence.

\section{Review of Related Literature}

\subsection{Structural Equation Models (SEM)}

SEM (Structural Equation Modeling) is a statistical technique that analyzes the pattern of relationship between the latent constructs (variables) and their indicators. SEM allows the analysis of multiple dependent and independent variables directly (7). SEM is applied to examine and justify a model instead of to design a theory. Therefore, the main requirement to use SEM is building a hypothetical model that consists of structural models and measurement models in the form of the path diagram based on justification theory (13). Principally, structural modeling equation (SEM) is a statistical technique for 
testing and estimating causal relationships using a combination of statistical data and qualitative causal assumptions (8). Modelling confirmation usually begins with a hypothesis that will be represented in the causal model.

\subsection{Strength Weakness Opportunities Threats (SWOT)}

SWOT matrix is a framework that helps managers to develop four types of strategies. A matrix is considered to be able to clearly describe how external opportunities and threats faced by the organization must be adapted to the strengths and weaknesses (23). SWOT factors are not independent of each other, yet there is a relationship between these components (14). Generally, the factor values in the SWOT are calculated based on the principle that the factors are independent from each other. The study found that the changes in weight factors can cause a change in strategic priorities, one of them using factor analysis. So the use a probabilistic method that measures the relationship between these factors is required in analyzing SWOT, so that the research offered a new method to arrange strategies SO, ST, WO and WT using factor analysis model significant of each piece variables with questionnaire (24).

\subsection{Graph Theory and Matrix Approach (GTMA)}

GTMA is a systematic approach that is used in a variety of subject areas. Conventional representation like block diagram, a causal diagram, effect diagram, and flow diagrams do not depict the interaction between these factors and are not suitable for further analysis and cannot be processed or expressed in mathematical form. Therefore, GTMA is the right method to be applied to analyse a problem further to obtain the best alternative (15). GTMA application has been reviewed in the literature to evaluate the intensity of the variables affecting other variables with graph theory and matrix approach (25), GTMA approach was used to a productivity index of manufacturing.

In this GTMA contains some parts, namely:

- Graph representation : describing relations / level of importance of each variable, in this case, the meant variables is a grouping strategy.

- Matrix representation : matrix represents the importance and weight in matrices. The weight of each variable is put diagonally, while the level of importance is put horizontally and vertically besides the location of the weight value on the diagonal.

- Function of permanent representation: the function of a permanent representation is a single solution value of the total value of matrix representation which is calculated using the formula determinants.

\section{Research Methods}

The first stage in this study is model development phase. It begins by determining the basis model from the previous studies as the reference to do research model development. There are two basic models which both discuss the increase in productivity. The first previous studies (7) explained that the organization and marketing has a major role in improving the company or an increase in productivity. In addition, the second previous studies (8) found that customer satisfaction comes from the expedience of products which become a measurement of the company to improve productivity. Thus, based on these two previous studies, this study used those two models as the basis research model that will be developed, in which these three variables (organization capability, production, and marketing system) have some influence on productivity.

The next stage is making the design of structural models that will be operated using the application of Structural Equation Models, namely AMOS. After that, the value of the loading factor from AMOS will appear on each indicators and variables. After having the SEM interpretation, these three significant variables are categorized into the scheme of SWOT based on data from the questionnaire. SWOT is used to classify the SWOT variable and analyse the strengths and weaknesses of internal and external of the object of research. From the result, some ideas of the strategies are formulated which is then discussed and validated by the speaker of the Ministry of Industry. So the results of this SWOT is the weight value of each idea strategy that has been prepared based on four sections, namely SO strategy, 
WO, ST and WT. Based on the output generated from SWOT, in GTMA, there are three stages performed towards the output; the first is to make a graph representation, then to establish the matrix representation from the result of weightings which have been obtained and analyzed, and the last is to count the permanent value of each matrix in each part of the strategy. The last stage in this research is the conclusions and suggestions. These are some of variables used in this research :

Organization Capability ( C )

Production (P)

Marketing system (S)

Sources of internal innovation (SI)

Sources of external innovation (SE)

Productivity (PR)

There are eleven hypotheses formulated in this study:

H1 : Organization capability has a direct influence on productivity improvement

$\mathrm{H} 2$ : The production has a direct influence on productivity improvement

H3 : Marketing system has a direct influence on the productivity improvement

$\mathrm{H} 4$ :The production has an influence on productivity improvement through the sources of internal innovation

H5 : Organization capability has an influence on productivity improvement through the sources of internal innovation

H6 : Marketing system has an influence on productivity improvement through the sources of internal innovation.

$\mathrm{H} 7$ : Sources of internal innovation has influence on the productivity improvement

H8 : the production has influence on the production improvement through the sources of external innovation

H9 : Organization capability has an influence on productivity improvement through the sources of external innovation

H10 : marketing system has an influence on productivity improvement through the sources of external innovation

H11 : the sources of external innovation has influence on productivity improvement

\section{Findings and Discussion}

The number of respondents participated in this study was 214 respondents. Table 2 shows Cronbach's alpha for each variable.

Table 2. Reliability Statistics Variable with Cronbach's alpha.

\begin{tabular}{|c|c|c|c|c|c|c|c|}
\hline No & Variabel & Indikator & $\begin{array}{c}\text { Cronbach's } \\
\text { alpha }\end{array}$ & No & Variabel & Indikator & $\begin{array}{c}\text { Cronbach's } \\
\text { alpha }\end{array}$ \\
\hline 1 & $\begin{array}{c}\text { Organization } \\
\text { Capability }\end{array}$ & $\begin{array}{l}\text { Learning ability (C1) } \\
\text { Power resource capability (C2) } \\
\text { Strategic planning ability (C3) } \\
\text { Work culture (C4) }\end{array}$ & .868 & 4 & $\begin{array}{l}\text { Sources of } \\
\text { internal } \\
\text { innovation } \\
\text { (SI) }\end{array}$ & $\begin{array}{l}\text { Background owner (SI1) } \\
\text { Labor (SI2) } \\
\text { Technology (SI3) }\end{array}$ & .832 \\
\hline 2 & $\begin{array}{l}\text { Production } \\
\text { (P) }\end{array}$ & $\begin{array}{l}\text { Work motivation (C5) } \\
\text { Leadership (C6) } \\
\text { Process (P1) } \\
\text { Product (P2) } \\
\text { Product Quality (P3) }\end{array}$ & .756 & 5 & $\begin{array}{l}\text { Sources of } \\
\text { external } \\
\text { innovation } \\
\text { (SE) }\end{array}$ & $\begin{array}{l}\text { Relation \& collaboration (SE1) } \\
\text { geographical location (SE2) } \\
\text { Government suppor (SE3) } \\
\text { Competitors (SE4) } \\
\text { Customer (SE5) }\end{array}$ & .838 \\
\hline 3 & $\begin{array}{l}\text { Marketing } \\
\text { system (S) }\end{array}$ & $\begin{array}{l}\text { Customer Service (S1) } \\
\text { Delivery accuracy (S2) } \\
\text { Responsibility (S3) } \\
\text { Market knowledge (S4) } \\
\text { Marketing Techniques (S5) }\end{array}$ & .852 & 6 & $\begin{array}{l}\text { Productivity } \\
\text { (PR) }\end{array}$ & $\begin{array}{l}\text { Work efficiency (PR1) } \\
\text { Investment (PR2) } \\
\text { Skills (PR3) } \\
\text { Result (PR4) } \\
\text { Work attitud (PR5) }\end{array}$ & .865 \\
\hline
\end{tabular}

From Table 2, there are 27 indicators that are taken. In addition, based on the Cronbach's alpha criteria, all items were taken. The study retained factor loadings greater than 0.50 for further analysis. Reliability of the factors was estimated using the Cronbach's alpha. A Cronbach's alpha value of greater than or equal to 0.7 is considered acceptable for the factor to be reliable (15). In this case, all the factors 
had a satisfactory value of Cronbach's alpha. Hence the factors are reliable. Here are Figure 1 shown the analysis results of full model testing and Table 3 shown the interpretation Model.

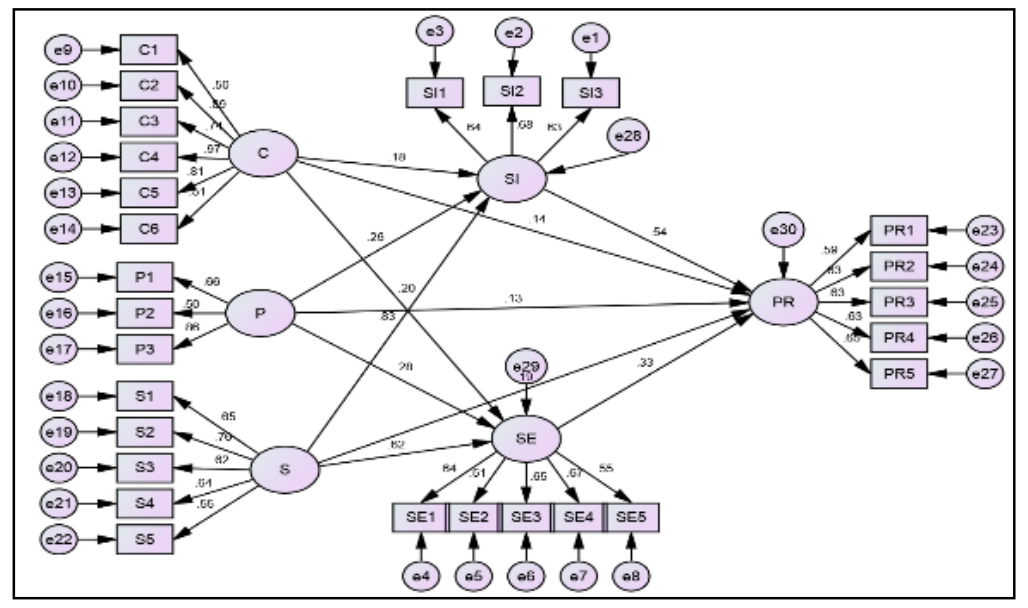

Figure 1. Full Model Testing.

Table 3. Interpretation of Model.

\begin{tabular}{cccc}
\hline Hipotesis & $\begin{array}{c}\text { C.R. } \\
(\mathbf{1 . 9 6})\end{array}$ & $\begin{array}{c}\mathbf{P} \\
(<\mathbf{0 . 0 5})\end{array}$ & Keputusan \\
\hline H1 & 2.210 & .027 & Signifikan \\
H2 & 1.744 & .081 & Tidak Signifikan \\
H3 & 1.210 & .226 & Tidak Signifikan \\
H4 & 2.800 & .005 & Signifikan \\
H5 & 2.486 & .013 & Signifikan \\
H6 & 6.816 & $* * *$ & Signifikan \\
H7 & 3.226 & .001 & Signifikan \\
H8 & 2.965 & .003 & Signifikan \\
H9 & 2.554 & .011 & Signifikan \\
H10 & 5.853 & $* * *$ & Signifikan \\
H11 & 3.539 & $* * *$ & Signifikan \\
\hline
\end{tabular}

Model fit

The measurement model indicated an acceptable model fit of the data $\operatorname{CMIN}(\chi 2)=235,297, \mathrm{p}=.000$; $\mathrm{CMIN} / \mathrm{DF}(\chi 2 / \mathrm{DF})=0,0015(<5) ; \mathrm{CFI}=0,803 ; \mathrm{TL} \mathrm{I}=0,875 ; \mathrm{IFI}=0.964 ; \mathrm{NFI}=0,901 ; \mathrm{RFI}=0.920$; GFI $=0,751$; and RMSEA $=0,760$. In addition, all the indicators loaded significantly on the latent constructs. The values indicate a reasonable fit to the measurement model. Further evidence of the reliability of the scale is provided in Table 4, which shows the composite reliability (CR) and average variance extracted (AVE) scores of the different factors obtained (15). CR of all the latent variables is greater than the acceptable limit of 0.70. The AVE for all the factors is greater than 0.5, which is acceptable). This shows the internal consistency of the variables used in the study. 
Table 4. Goodness of Fit Model Analysis

\begin{tabular}{|c|c|c|c|c|c|c|c|}
\hline \multirow[b]{2}{*}{ Indicator } & & \\
\hline & Estimate & $\begin{array}{c}\text { C.R } \\
(>0,6- \\
0,7) \\
\end{array}$ & $\begin{array}{c}\text { ave } \\
(>0,5)\end{array}$ & Indicator & Estimate & $\begin{array}{c}\text { C.R } \\
(>0,6- \\
0,7) \\
\end{array}$ & $\begin{array}{c}\text { ave } \\
(>0,5)\end{array}$ \\
\hline SI1 & 0,685 & & & P3 & 0,500 & & \\
\hline SI2 & 0,630 & 0,7 & 0,6 & P2 & 0,657 & 0,7 & 0,5 \\
\hline SI3 & 0,647 & & & P1 & 0,615 & & \\
\hline SE3 & 0,514 & & & S3 & 0,757 & & \\
\hline SE2 & 0,641 & & & S2 & 0,652 & & \\
\hline SE1 & 0,668 & 0,7 & 0,6 & S1 & 0,639 & 0,8 & 0,6 \\
\hline SE4 & 0,553 & & & S4 & 0,553 & & \\
\hline SE5 & 0,738 & & & S5 & 0,625 & & \\
\hline C3 & 0,893 & & & PR3 & 0,629 & & \\
\hline C2 & 0,501 & & & PR4 & 0,655 & & \\
\hline C1 & 0,971 & 09 & 05 & PR5 & 0,630 & 0,8 & 0,6 \\
\hline C4 & 0,809 & 0,9 & 0,5 & PR2 & 0,593 & & \\
\hline C5 & 0,514 & & & PR1 & 0,592 & & \\
\hline
\end{tabular}

Based on conclusion of hypotheses from full model testing, the next stage is to use the output for the SWOT analysis. Here are Figure 2 shown the scheme proccess to classify these indicators (for example the significant hypothesis 1) in model used to make a questionnaire is used as a framework in developing the strategies of strengths and weaknesses with using the indicators each variable, which are validated by the speakers and people in charge and have authority in the BPIPI.

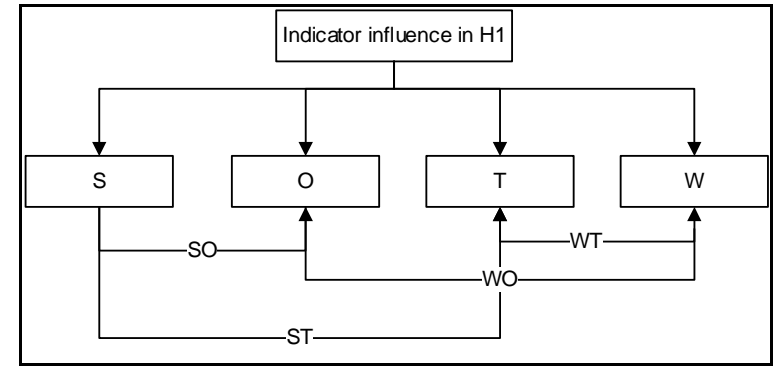

Figure 2. Scheme Proccess hypotheses 1 (H1).

These frameworks is used to control and provide facilitators to the footwear centres all over areas in Indonesia. These people are sent directly by the Ministry of Industry that have been classified based on SO, WO, ST and WT points.

Based on the classification of SWOT, the priority strategies is then formulated using the GTMA method with the phases shown in Figure 3 (example graph for SO Strategy), and using the matrix representation from Table 5 (example matrix representation for SO Strategy), as well as the the result of calculation of permanent matrix of each formulation of strategies from the table 6 . 


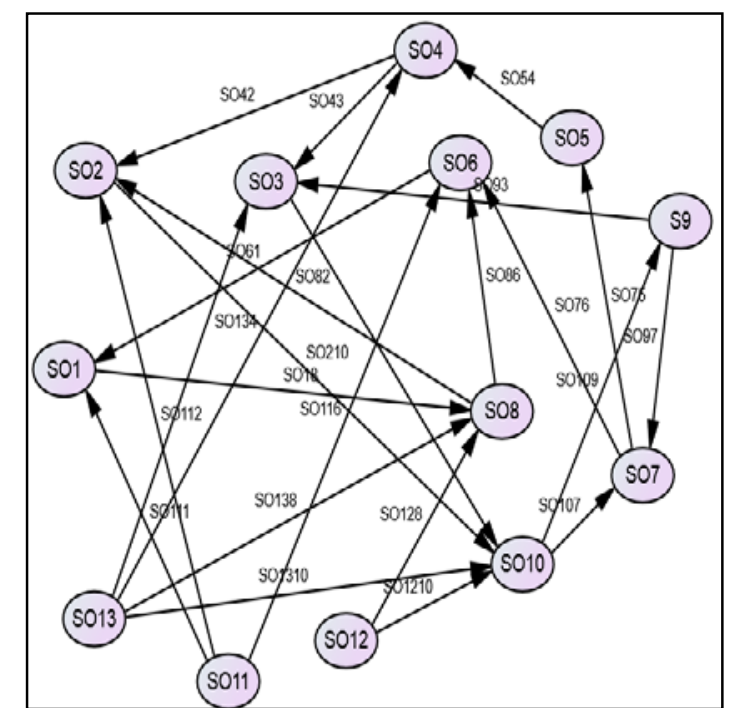

Figure 3. Graph Strategy.

Table 5. Matrix Representation.

\begin{tabular}{lccccccccccccc}
\hline & SO1 & SO2 & SO3 & SO4 & SO5 & SO6 & SO7 & SO8 & SO9 & SO10 & SO11 & SO12 & SO13 \\
\hline SO1 & 0 & 4 & 5 & 5 & 4 & 3 & 5 & 6 & 5 & 4 & 2 & 3 & 5 \\
SO2 & 6 & 0 & 5 & 4 & 6 & 4 & 5 & 2 & 4 & 7 & 2 & 3 & 4 \\
SO3 & 5 & 5 & 0 & 4 & 3 & 4 & 5 & 4 & 2 & 6 & 4 & 4 & 3 \\
SO4 & 5 & 6 & 6 & 0 & 2 & 4 & 4 & 4 & 3 & 5 & 4 & 5 & 3 \\
SO5 & 6 & 4 & 7 & 8 & 0 & 4 & 3 & 4 & 4 & 5 & 5 & 3 & 4 \\
SO6 & 7 & 6 & 6 & 6 & 6 & 0 & 3 & 2 & 5 & 3 & 2 & 5 & 4 \\
SO7 & 5 & 5 & 5 & 6 & 7 & 7 & 0 & 3 & 2 & 2 & 3 & 4 & 4 \\
SO8 & 4 & 8 & 6 & 6 & 6 & 8 & 7 & 0 & 4 & 3 & 3 & 2 & 3 \\
SO9 & 5 & 6 & 8 & 7 & 6 & 5 & 8 & 6 & 0 & 2 & 3 & 3 & 4 \\
SO10 & 6 & 3 & 4 & 5 & 5 & 7 & 8 & 7 & 8 & 0 & 3 & 2 & 3 \\
SO11 & 8 & 8 & 6 & 6 & 5 & 8 & 7 & 7 & 7 & 7 & 0 & 3 & 4 \\
SO12 & 7 & 7 & 6 & 5 & 7 & 5 & 6 & 8 & 7 & 8 & 7 & 0 & 4 \\
SO13 & 5 & 6 & 7 & 7 & 6 & 6 & 6 & 7 & 6 & 7 & 6 & 6 & 0 \\
\hline
\end{tabular}

Table 6. Permanent matrix.

\begin{tabular}{ccc}
\hline $\begin{array}{c}\text { Strategy } \\
\text { Formulation }\end{array}$ & Permanent matrix & Priority \\
\hline WT & $226,459,859,415.80$ & 1 \\
SO & $6,125,469,919.75$ & 2 \\
WO & $5,331,254,378.42$ & 3 \\
ST & $528,009,005.60$ & 4 \\
\hline
\end{tabular}

\section{Conclusion}

The SMEs capabilities and resources, both internal and external innovation, have simultaneously given significant influence to the development of SMEs. In the beginning, there are four considerations of strategy formulation based on SWOT framework, namely strategy of SO, ST, WO and WT. From these four strategies, the priority level is calculated based on the influence value in SMEs Cibaduyut as well as the level of importance of the strategy based on the data acquired from the speakers from BPIPI. The result shows that the first priority level is strategy of WT, which has the greatest permanent value matrix. 
Strategy of WT formulation is a strategy that considers the weakness in facing problems. Thus, this strategy is suggested to be applied to the condition of SMEs leather footwear center in Cibaduyut.

\section{Future Research}

Variables that used in this research can be more explored, so that the formulation of strategies could consider more variables/indicators. For example, by considering the research variable and its development, financial variables, and more. From the results, it is determined that SMEs should be able to understand its strengths and weaknesses, and should do some strategies based on its weaknesses and threats that might interfere. They also needs to conduct a feasibility study calculations to measure the feasibility of the implementation of the proposed strategy.

\section{References}

1. Gu Q, Jiang W, Wang GG. Effects of external and internal sources on innovation performance in Chinese high-tech SMEs: A resource-based perspective. J Eng Technol Manag. 2016 Apr 1;40:76-86.

2. $\quad$ Kurt S, Kurt Ü. Innovation and Labour Productivity in BRICS Countries: Panel Causality and Co-integration. Procedia - Soc Behav Sci. 2015 Jul 3;195:1295-302.

3. Acosta M, Coronado D, Romero C. Linking public support, R\&amp;D, innovation and productivity: New evidence from the Spanish food industry. Food Policy. 2015 Nov 1;57:50-61.

4. Chao ÁD, Gonzále JS, Sellens JT. ICT, innovation, and firm productivity: New evidence from small local firms. J Bus Res. 2015;68(7):1439-44.

5. $\quad$ Eristina RR. Sumber Inovasi IKM. Tek dan Manaj Ind ITB, Bandung. 2013;

6. Yueh H-P, Lu M-H, Lin W. Employees' acceptance of mobile technology in a workplace: An empirical study using SEM and fsQCA. J Bus Res. 2016 Jun 1;69(6):2318-24.

7. Holmlund M, Kowalkowski C, Biggemann S. Organizational behavior in innovation, marketing, and purchasing in business service contexts-An agenda for academic inquiry. J Bus Res. 2016 Jul 1;69(7):2457-62.

8. $\quad$ Subramanian N, Gunasekaran A, Yu J, Cheng J, Ning K. Expert Systems with Applications Customer satisfaction and competitiveness in the Chinese E-retailing: Structural equation modeling ( SEM ) approach to identify the role of quality factors. Expert Syst Appl. 2014;41(1):69-80.

9. Crespi G, Zuniga P. Innovation and Productivity: Evidence from Six Latin American Countries. World Dev. 2012;40(2):273-90.

10. Barroso Simao L, Gouveia Rodrigues R, Madeira MJ. External relationships in the organizational innovation. RAI Rev Adm e Inovação. 2016 Jul 1;13(3):156-65.

11. Theeke M. The effects of internal and external competition on innovation breadth. J Bus Res. 2016 Sep 1;69(9):3324-31.

12. Hsiao C, Chang J, Tang K. Telematics and Informatics Exploring the influential factors in continuance usage of mobile social Apps : Satisfaction , habit , and customer value perspectives. Telemat INFORMATICS. 2016;33(2):342-55.

13. Andersson U, Dasí À, Mudambi R, Pedersen T. Technology, innovation and knowledge: The importance of ideas and international connectivity. J World Bus. 2016 Jan 1;51(1):153-62.

14. Shariatmadari M, Homayoun A, Hedayat P. Using SWOT analysis and SEM to prioritize strategies in Foreign exchange market in Iran. Procedia - Soc Behav Sci. 2013;99:886-92.

15. Jain V, Raj T. Modeling and analysis of FMS performance variables by ISM, SEM and GTMA approach. Int J Prod Econ. 2016 Jan 1;171:84-96.

16. Baumann J, Kritikos AS. The link between R\&amp;D, innovation and productivity: Are micro firms different? Res Policy. 2016 Jul 1;45(6):1263-74.

17. Herciu M. Measuring International Competitiveness of Romania by Using Porter's Diamond and Revealed Comparative Advantage. Procedia Econ Financ. 2013 Jan 1;6:273-9.

18. Wu K-J, Tseng M-L, Chiu ASF. Using the Analytical Network Process in Porter's Five Forces 
Analysis - Case Study in Philippines. Procedia - Soc Behav Sci. 2012;57:1-9.

19. Chan FTS, Chong AYL. A SEM-neural network approach for understanding determinants of interorganizational system standard adoption and performances. Decis Support Syst. 2012;54(1):621-30.

20. Gelderman CJ, Semeijn J, Mertschuweit PP. The impact of social capital and technological uncertainty on strategic performance: The supplier perspective. J Purch Supply Manag. 2016 Sep 1;22(3):225-34.

21. Shao BBM, Lin WT. Assessing output performance of information technology service industries: Productivity, innovation and catch-up. Int J Prod Econ. 2016 Feb 1;172:43-53.

22. Sulistyo H, Siyamtinah. Innovation capability of SMEs through entrepreneurship, marketing capability, relational capital and empowerment. Asia Pacific Manag Rev. 2016 Dec 1;21(4):196203.

23. David FR. Strategic Management Concepts And Cases. 2013. 685 p.

24. Vijver FJR van de. Capturing bias in structural equation modeling. In: Cross-cultural analysis Methods and applications. New York: Routledge/Taylor \& Francis Group; 2011.

25. Wilson robin J. graph theory. fourth edi. malaysia: prentice hall; 1995. 